\title{
TU/e EmonOWEN

\section{Stress stabilization of the orthorhombic and hexagonal phases of UHM PE gel-spun fibres}

Citation for published version (APA):

Rastogi, S., \& Odell, J. A. (1993). Stress stabilization of the orthorhombic and hexagonal phases of UHM PE gelspun fibres. Polymer, 34(7), 1523-1527. https://doi.org/10.1016/0032-3861(93)90872-8

DOI:

10.1016/0032-3861(93)90872-8

Document status and date:

Published: 01/01/1993

\section{Document Version:}

Publisher's PDF, also known as Version of Record (includes final page, issue and volume numbers)

\section{Please check the document version of this publication:}

- A submitted manuscript is the version of the article upon submission and before peer-review. There can be important differences between the submitted version and the official published version of record. People interested in the research are advised to contact the author for the final version of the publication, or visit the $\mathrm{DOI}$ to the publisher's website.

- The final author version and the galley proof are versions of the publication after peer review.

- The final published version features the final layout of the paper including the volume, issue and page numbers.

Link to publication

\section{General rights}

Copyright and moral rights for the publications made accessible in the public portal are retained by the authors and/or other copyright owners and it is a condition of accessing publications that users recognise and abide by the legal requirements associated with these rights.

- Users may download and print one copy of any publication from the public portal for the purpose of private study or research.

- You may not further distribute the material or use it for any profit-making activity or commercial gain

- You may freely distribute the URL identifying the publication in the public portal.

If the publication is distributed under the terms of Article 25fa of the Dutch Copyright Act, indicated by the "Taverne" license above, please follow below link for the End User Agreement:

www.tue.nl/taverne

Take down policy

If you believe that this document breaches copyright please contact us at:

openaccess@tue.nl

providing details and we will investigate your claim. 


\title{
polymer communications
}

\author{
Stress stabilization of the orthorhombic and hexagonal phases of \\ UHM PE gel-spun fibres
}

\author{
S. Rastogi† and J. A. Odell* \\ H. H. Wills Physics Laboratory, Tyndall Avenue, University of Bristol, Bristol, BS8 1TL, UK \\ (Received 7 September 1992)
}

\begin{abstract}
In highly oriented polymers, stress can stabilize fibres against melting by favouring the low entropy fibrillar state against the high entropy melt. In this work we have investigated the thermal stability of gel-spun ultra-high modulus polyethylene subjected to tensile stress. The Daresbury X-ray synchrotron radiation source and optical microscopy have been utilized to follow dynamically the transformation, melting and recrystallization of fibres, under optimum conditions of controlled stress. The orthorhombic phase is stable up to $164^{\circ} \mathrm{C}$, after which the crystals transform into a hexagonal phase which can be stable up to temperatures as high as $179^{\circ} \mathrm{C}$. Whilst this is the greatest thermal stability reported for the orthorhombic phase, the question of the ultimate stability is still unanswered and is presently limited by the effectiveness of the stress transfer to the fibrils.
\end{abstract}

(Keywords: stress; hexagonal; orthorhombic; gel-spun; polyethylene)

\section{Introduction}

Application of high pressures normally promotes stability of the solid phase. It has long been recognized that this is the case for semicrystalline polymer systems, where crystallization at high temperatures and pressures reveals novel morphological features. For example, in bulk polyethylene, the application of pressure can stabilize the normal orthorhombic (o) crystals, and enable a stable two-dimensional hexagonal (h) crystal structure, with an anomalously high longitudinal mobility of the polymer chains ${ }^{1}$. It is thought that this high chain mobility in $h$ phase is responsible for chain folding reorganization towards thicker or even chain-extended crystals ${ }^{2}$.

In highly oriented polymers, stress can play a similar role to pressure; by energetically favouring the low entropy fibrillar crystal state it can stabilize fibres against melting of the o phase and enable observation of a stable $h$ phase. Based on observations of birefringence, Odell et al. $^{3}$ reported an increase in melting temperature of constrained interlocking melt-produced shish-kebabs from 136 to $160^{\circ} \mathrm{C}$. Smook and Pennings ${ }^{4}$ reported similar observations on ultra-high molecular weight polyethylene (UHM PE) fibrils prepared by the surface growth technique with enhancement of the melting point up to $180^{\circ} \mathrm{C}$. Using gel-spun fibres, Van Aerle and co-workers ${ }^{5,6}$ combined such observations with $\mathrm{X}$-ray studies to reveal the stability of the o phase, the o- $h$ transition and melting of the $h$ phase. These workers report the $\mathrm{o}-\mathrm{h}$ transition at $152^{\circ} \mathrm{C}$, and melting of the h phase above $175^{\circ} \mathrm{C}$.

It is our belief that the ultimate stability of oriented material depends largely upon the effectiveness of the constraints applied to the fibrous material. In the present

* To whom correspondence should be addressed

† Present address: Centre for Polymers and Composites, Eindhoven University of Technology, PO Box 513,5600 MB Eindhoven, The Netherlands work we set out to establish the best possible constraints upon the sample against contraction and melting. We observe birefringence, stress in the fibrils and, using the Daresbury Synchroton Radiation Source (DSRS), we dynamically record the X-ray scattering and hence identify the transformation, melting and recrystallization of the material. Here we will show the attainment of $\mathrm{o}-\mathrm{h}$ transition at temperature as high as $164^{\circ} \mathrm{C}$, at atmospheric pressure.

Achievement of the most effective constraints presents two principal requirements. First, the sample must be embedded in a matrix material which can support a high shear and compressive stress at elevated temperature. We found a u.v. curing low viscosity cyanoacrylate adhesive to be most effective. Second, the stress must be effectively transferred from the polymer/matrix interface into the interior of the polymer. This is best achieved by maximizing the surface area, in practice utilizing very fine fibrils. We used Allied Chemicals Spectrum 900, a highly oriented gel-spun fibre with an average fibrillar diameter of around $60 \mu \mathrm{m}$.

\section{Experimental and results}

Birefringence. Figure 1 shows the birefringence of the fibrils observed in the hot-stage polarizing microscope as a function of temperature. The fibrils placed in between cover slips are embedded within cured cyanoacrylate. As can be seen, the birefringence falls only slightly up to around $170^{\circ} \mathrm{C}$; the final traces of birefringence are observable beyond $179^{\circ} \mathrm{C}$. When a sample that has been almost completely melted, as assessed by birefringence, is cooled to recrystallize the material, then we see recrystallization of oriented material, presumably nucleated by the remaining fibrillar cores.

Stress. In the present work we studied stress dependence upon temperature in the constrained fibres. Here fibres are immersed within cyanoacrylate except for 

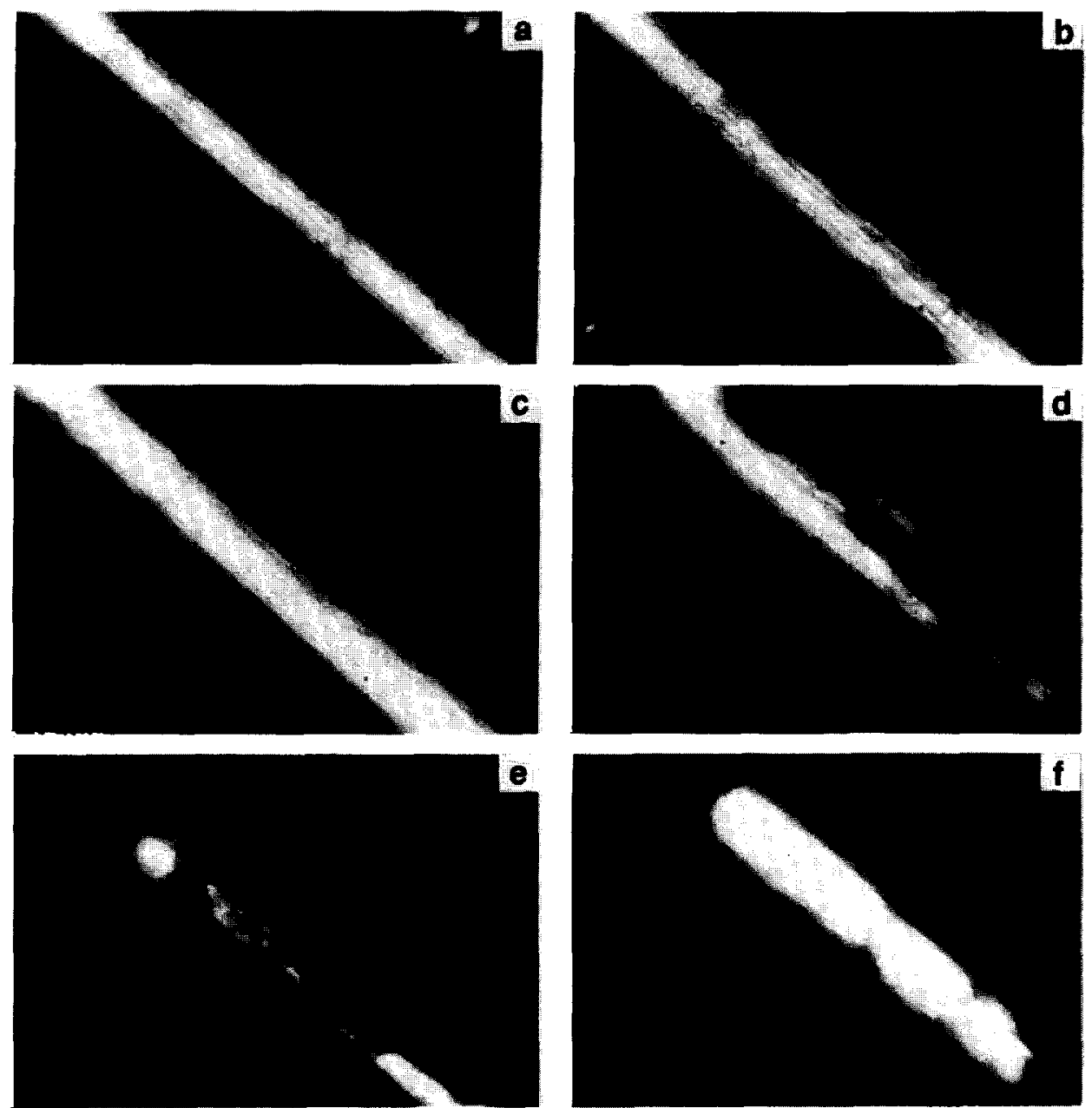

$100 \mu \mathrm{m}$

Figure 1 Polarizing microscope observations of a constrained fibril during heating: (a) $40^{\circ} \mathrm{C}$; (b) $147^{\circ} \mathrm{C}$; (c) $166^{\circ} \mathrm{C}$; (d) $170.5^{\circ} \mathrm{C}$; (e) $179^{\circ} \mathrm{C}$; (f) after recrystallization at $120^{\circ} \mathrm{C}$

a small region (about $1 \mathrm{~mm}$ long) in the centre, and are kept under stress by clamping their ends and maintaining length. Any relaxation of stress within these fibres could be measured to a precision of $1 \mathrm{MPa}$. On heating to $140^{\circ} \mathrm{C}$ within a well calibrated and insulated chamber, no significant change in stress is observed (Figure 2). A gradual increase in stress is measured on heating above $140^{\circ} \mathrm{C}$ and below $164^{\circ} \mathrm{C}$. A sharp decrease in stress to zero (within the experimental limitations) occurs just above $164^{\circ} \mathrm{C}$. A decrease in the stress corresponds to relaxation within the fibre. While cooling from $170^{\circ} \mathrm{C}$ down to $130^{\circ} \mathrm{C}$ the stress in the fibre remains almost zero. Once the temperature falls below $130^{\circ} \mathrm{C}$, down to $90^{\circ} \mathrm{C}$ a continuous increase in stress from 0 to $190 \mathrm{MPa}$ is measured. Below $90^{\circ} \mathrm{C}$ the load remains nearly constant. This increase in load on cooling corresponds to contraction of the fibre when the constraints are released.

$X$-ray observations - stability of $o$ and $h$ phases. To reveal the molecular changes within the fibre, and to know the corresponding variation in stress with temperature in the constrained fibres, we used timeresolved wide-angle X-ray scattering (WAXS) facilities at DSRS. A two-dimensional detector is used for the fast collection of the data. This is one of the experimental necessities to be discussed later. Figure $3 a$ shows (1 110$)$ and $(200) \mathrm{o}$ reflections at $162^{\circ} \mathrm{C}$ of a well oriented,

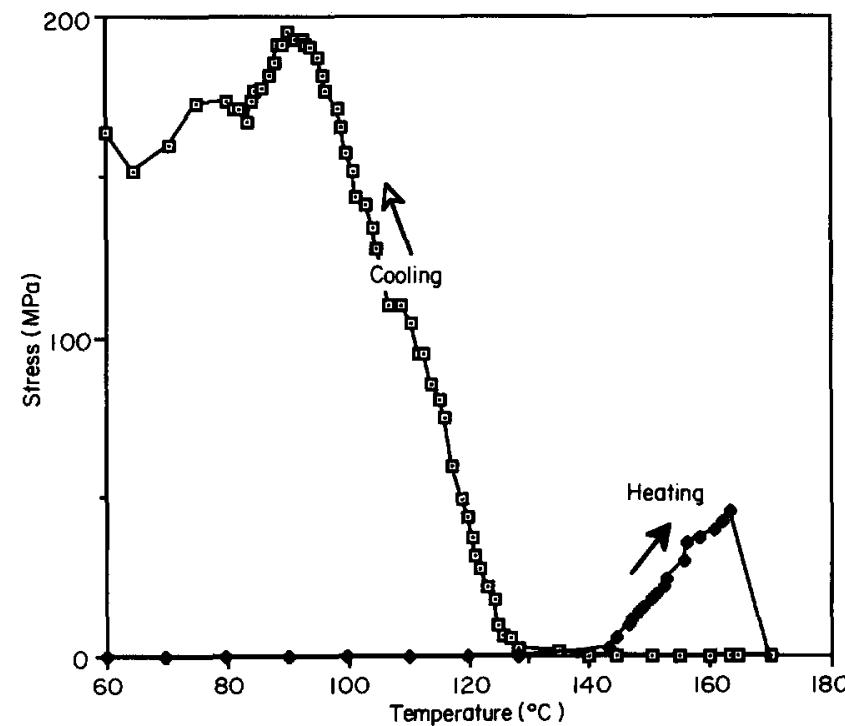

Figure 2 Stress versus temperature for constrained fibrils during heating up to $170^{\circ} \mathrm{C}$ and subsequent cooling

gel-spun, well constrained fibre immersed within the cyanoacrylate. On raising temperature by only $2^{\circ} \mathrm{C}$ appearance of the $\{100\} \mathrm{h}$ reflection is seen (Figure $3 b$ ). It should be noted that as the $\{100\} \mathrm{h}$ reflection strengthens, the $(110)$ and $(200)$ o reflections weaken. On leaving at 

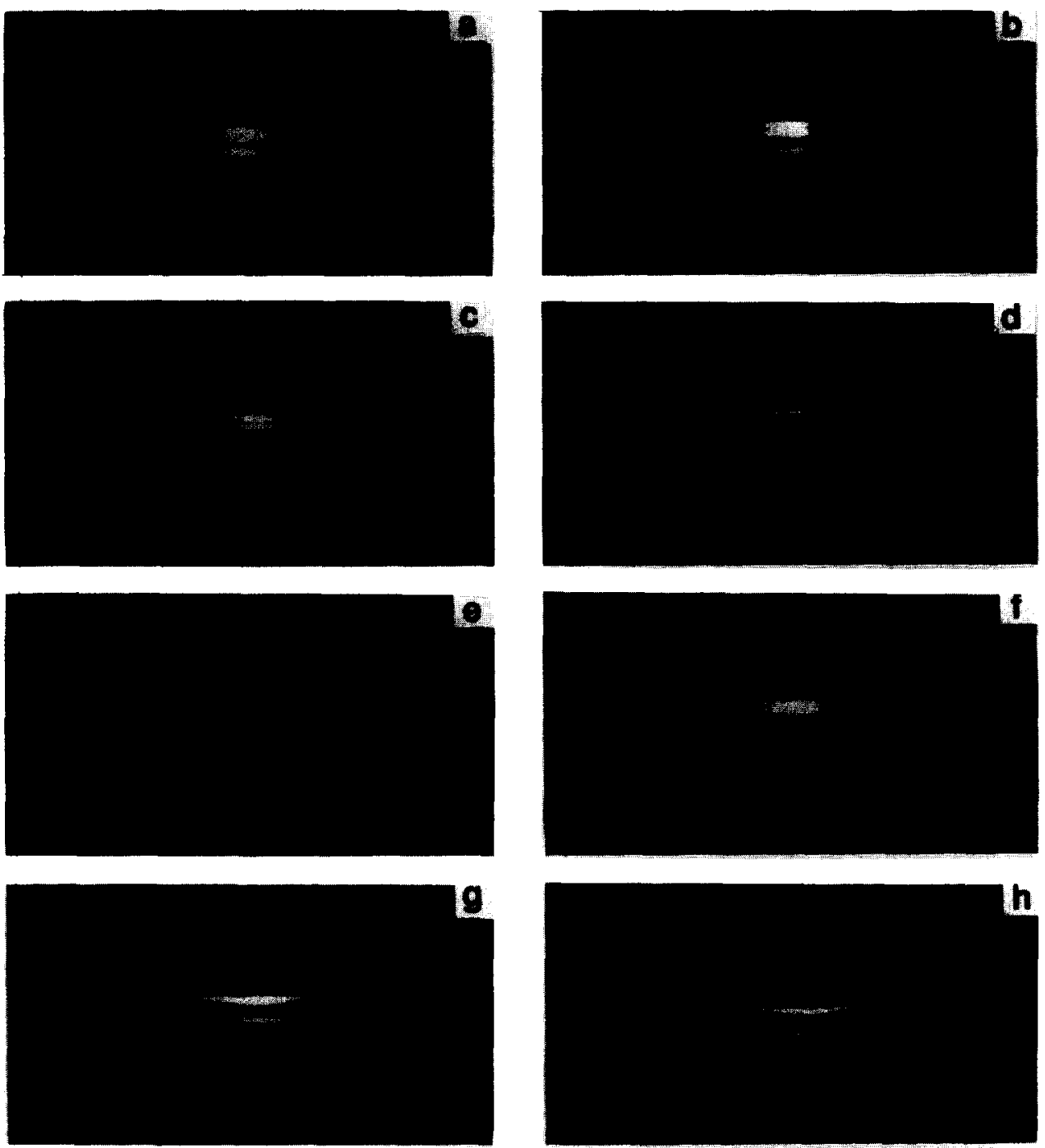

Figure 3 X-ray diffraction patterns of constrained fibrils during heating:(a) $162^{\circ} \mathrm{C}$;(b)-(d) $164^{\circ} \mathrm{C}$; and cooling: (e) $157^{\circ} \mathrm{C} ;\left(\right.$ (f) $152^{\circ} \mathrm{C} ;(\mathrm{g}) 135^{\circ} \mathrm{C}$; (h) $86^{\circ} \mathrm{C}$

$164^{\circ} \mathrm{C}$ for a longer time (Figure $3 c$ ) it is observed that while the $\{100\} \mathrm{h}$ reflection increases in intensity and (1 10), (200) o reflections diminish in intensity, scattering from the amorphous region in the form of a halo occurs. Figure $3 d$ shows the presence of the h phase together with scattering from the amorphous region at the background of these reflections. Figure $3 d$ also shows that on leaving the sample within the $h$ phase for a longer time, loss in orientation occurs. On heating the sample further, $4-6^{\circ} \mathrm{C}$ above $\mathrm{o}-\mathrm{h}$ transition temperature, the sample breaks. But on cooling below $164^{\circ} \mathrm{C}$, at $157^{\circ} \mathrm{C}$ (Figure 3e), the reappearance of $(110)$ and $(200)$ o reflections is seen along with the weakening of $\{100\}$ reflection of the $h$ phase. No change in intensity of the amorphous region is seen. This indicates that on cooling, the first order phase transition from $h$ to $o$ phase in the fibres occurs, while the amorphous region does not crystallize. On leaving for longer times at $157^{\circ} \mathrm{C}$ (Figure $\left.3 f\right)$ the intensity of $h\{100\}$ reflection decreases continuously whereas intensity of o (1 10$)$ and $(200)$ reflections increases. Figure $3 g$ shows the presence of (110) and (200) o reflections together with amorphous scattering at $135^{\circ} \mathrm{C}$, whereas the $\{100\}$ reflection from the $h$ phase completely disappears. Partial orientation in the fibre is maintained. When the fibre is cooled further below $130^{\circ} \mathrm{C}$, intensity from the amorphous region starts disappearing whereas the intensity of $(110)$ and $(200)$ o reflections increases continuously. This further crystallization is seen as the appearance of an arc and the complete disappearance of scattering from the amorphous region at $86^{\circ} \mathrm{C}($ Figure $3 h)$.

\section{Discussion}

The role of stress in stabilizing the o phase is clear. The stress energetically favours the low entropy chainextended fibrils against the high entropy contracted melt, analogous to the role of pressure, which energetically favours the high density crystalline phase. It is clear from comparison of Figures 2 and 3 that once the stress begins to drop, the o phase is no longer stable. In the present work, due to the high quality of constraints, we have managed to maintain a high stress beyond $160^{\circ} \mathrm{C}$, and this has enabled stabilization of the o phase, as revealed by Figure $3 c$, up to the unprecedented temperature of $164^{\circ} \mathrm{C}$.

Beyond $164^{\circ} \mathrm{C}$ the crystals do not melt but transform into the $h$ phase, together with a drop in stress to levels that were too low to be recorded $(<1 \mathrm{MPa})$. Even though externally applied stresses are very low in the $h$ phase they are still essential for stability; if constraints are removed then the $h$ phase melts immediately. The reduction in stress is partly related to a progressive 

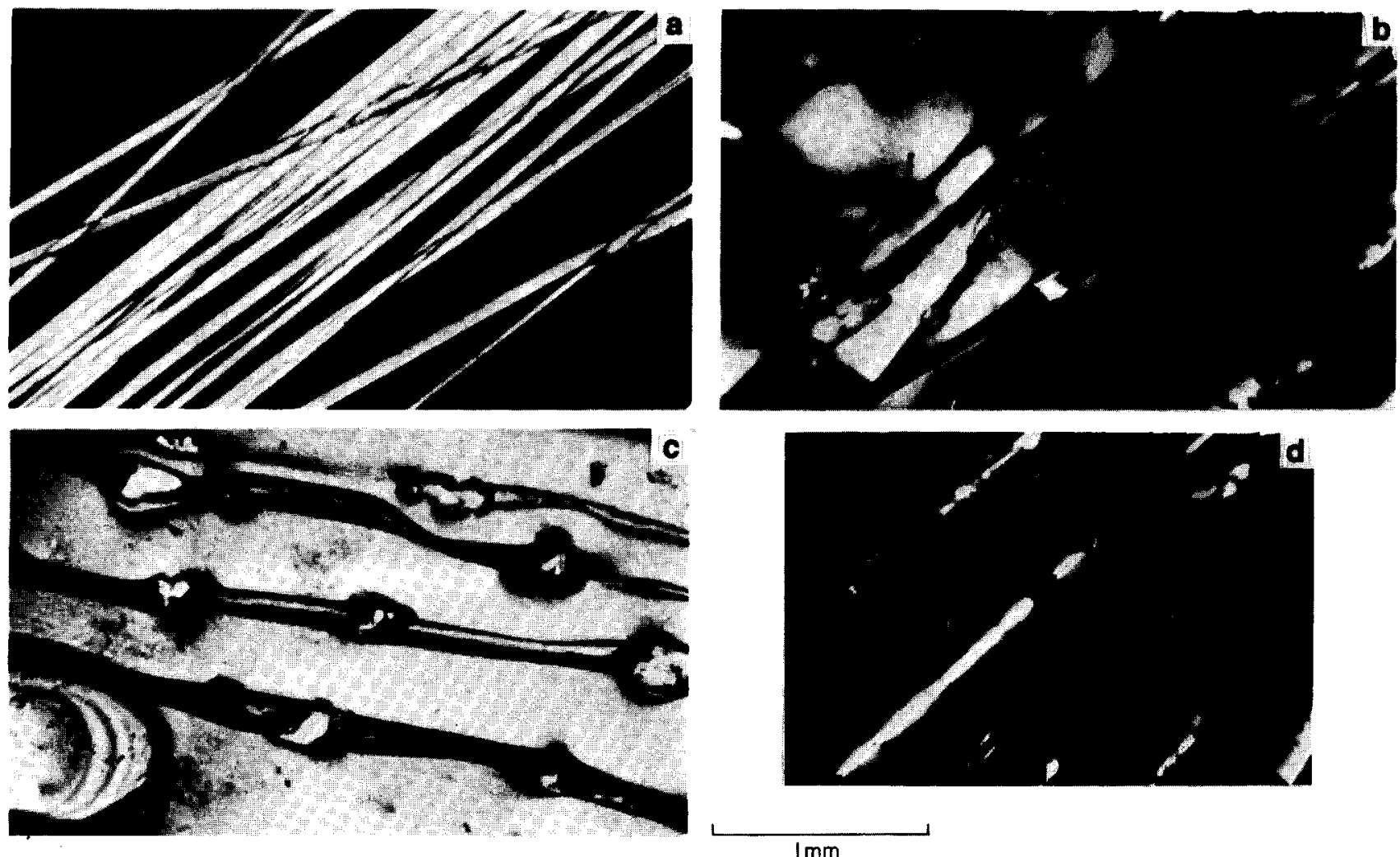

Figure 4 (a) Low magnification polarizing microscope observation of constrained fibrils at room temperature; (b) after heat-treatment up to $175^{\circ} \mathrm{C}$; (c) bright field view after heat treatment to $175^{\circ} \mathrm{C}$; (d) polarizing micrograph at $179^{\circ} \mathrm{C}$

decrease in crystallinity (to around $15 \%$ as assessed by integrated X-ray intensity in Figure 3e). It may also be related to the often reported high chain mobility of the $h$ phase ${ }^{1,2}$. Nevertheless, it is curious that the low entropy $h$ phase appears stable with such a small applied external stress.

We would expect that the partially molten $h$ fibril would consist of very fine crystal cores within a melt matrix, perhaps more than $3000 \AA$ apart ${ }^{7}$. As the material is recrystallized on cooling, the $h$ cores retransform to o (Figure $3 g$ ) with only o phase present at $157^{\circ} \mathrm{C}$. These observations are in close agreement with observations of the $\mathrm{h}-\mathrm{o}$ transition under pressure ${ }^{8}$. Below $130^{\circ} \mathrm{C}$, molten matrix material recrystallizes onto these nuclei (Figure 1f). Although by birefringence the crystallized material is overall oriented by the nuclei, it is clear from Figure $3 h$ that the orientation is much weaker. We believe this is due to recrystallization into a twisting $c$ axis overgrowth shish-kebab, which can occur when the nuclei are widely spaced $^{7}$. Recrystallization of the melt material below $130^{\circ} \mathrm{C}$ leads to recovery of the stress (Figure 2).

In the light of this composite view of an $h$ fibre at high temperature, it is possible that the stresses on the $h$ cores are much greater than the externally applied stresses. This could be due in part to their reduced volume fraction, but also to the fact that contraction of $h$ cores would require shearing through the very viscous UHM PE melt, which could generate high stresses that would not be seen externally.

It is worth noting that the results recently reported by Van Aerle et $a l^{6}$ are based upon partially stretched material, where the chains are not fully extended. It is likely that the $h$ phase in such material would be much less stable, since it can relax its stress internally by chain mobility without contraction through the melt. The chain mobility within the $h$ phase in the partially drawn material (relative to the fibre having full chain extension) will be much more prominent, as the thermodynamic driving force will favour full chain extension.

The present stability of the o phase at $164^{\circ} \mathrm{C}$ is the greatest reported. But the question of the ultimate stability of the o phase is still unanswered. Constraints, even in this experiment, are limited by the adhesion, mechanical and thermal stability of the matrix. Figure 4 shows a low magnification view at room temperature before treatment (Figure 4a) and after heat treatment (Figures $4 b-d$ ) of the same sample as shown in Figure 1.

On heating the constrained fibres above $150^{\circ} \mathrm{C}$ we observe a progressive process of retraction and loss of birefringence of parts of the fibrils. As the fibrils attempt to contract, so stress is transferred to the cyanoacrylate matrix, showing as stress birefringence (Figure $4 b$ ). Retraction is always accompanied by a breakdown of the matrix material, the original fibre channels rupturing sideways as shown in Figure $4 c$ (bright field optical micrograph). In other parts of the material, where the performance of the matrix is better, the fibres can remain locally constrained and highly birefringent up to temperatures as high as $179^{\circ} \mathrm{C}$ (Figure $4 d$ ).

\section{Conclusions}

Although we have demonstrated greatly enhanced stability of the o phase with stress, our findings suggest that the principal limitation to stability is still the quality of constraint. We speculate that etching of these fibres, to improve matrix adhesion, and use of better matrices like ceramics, which can withstand high temperatures without any loss in constraint efficiency, may further 
enhance the stability of the o phase and hence the melting temperature of UHM PE fibres. Potential applications of high-temperature high-modulus polyolefins do not require any illustration.

\section{Acknowledgement}

The financial support of SERC for this work is gratefully acknowledged. The authors are also grateful for the facilities (of station 8.2) of the Daresbury Synchrotron Radiation Source.

\section{References}

1 Bassett, D. C., Block, S. and Piermarini, G. J. J. Appl. Phys. 1974, 45,4146

2 Hikosaka, M. Polymer 1990, 31, 458

3 Odell, J. A., Grubb, D. T. and Keller, A. Polymer 1978, 19, 617

4 Smook, J. and Pennings, A. J. Colloid Polym. Sci. 1984, 262, 712

5 Van Aerle, N. A. J. M. and Lemstra, P. J. Polym. J. 1988, 20, 131

6 Van Aerle, N. A. J. M., Lemstra, P. J. and Braam, A. W. M. Polym. Commun. 1989, 30, 7

7 Bashir, Z. and Odell, J. A. J. Mater. Sci. in press

8 Rastogi, S., Hikosaka, M., Kawabata, H. and Keller, A. Macromolecules 1991, 24, 6384 